\title{
International Survey on the Management of Necrotizing Enterocolitis
}

\author{
Augusto Zani ${ }^{1}$ Simon Eaton ${ }^{2}$ Prem Puri ${ }^{3}$ Risto Rintala ${ }^{4}$ Marija Lukac ${ }^{5}$ Pietro Bagolan ${ }^{6}$ \\ Joachim F. Kuebler ${ }^{7}$ Michael E. Hoellwarth ${ }^{8}$ Rene Wijnen ${ }^{9}$ Juan Tovar ${ }^{10}$ \\ Agostino Pierro ${ }^{11}$; on behalf of the EUPSA Network
}

${ }^{1}$ Department of Pediatric Surgery, Sapienza University of Rome, Rome, Italy

2 Department of Paediatric Surgery, University College London, Institute of Child Health, London, United Kingdom

${ }^{3}$ Department of Pediatric Surgery, National Children's Research Centre, Dublin, Ireland

${ }^{4}$ Department of Paediatric Surgery, Hospital for Children and Adolescents, Helsinki, Finland

${ }^{5}$ Department of Pediatric Surgery, Faculty of Medicine, University Children's Hospital, Belgrade, Serbia

${ }^{6}$ Department of Medical and Surgical Neonatology, Bambino Gesù Children's Hospital, Rome, Italy

${ }^{7}$ Department of Pediatric and Adolescent Surgery, Medical University of Graz, Graz, Austria

${ }^{8}$ Department of Pediatric Surgery, Hannover Medical School, Hannover, Germany

${ }^{9}$ Department of Surgery, Radboud University Nijmegen Medical Centre, Nijmegen, The Netherlands

${ }^{10}$ Department of Pediatric Surgery, Hospital Universitario La Paz, Madrid, Spain

${ }^{11}$ Department of Paediatric Surgery, The Hospital for Sick Children, Toronto, Ontario, Canada,

Eur J Pediatr Surg 2015;25:27-33.
Address for correspondence Agostino Pierro, MD, Department of Paediatric Surgery, The Hospital for Sick Children, 555 University Avenue, Toronto, Ontario, Canada M5G 1X8 (e-mail: agostino.pierro@sickkids.ca).

\begin{abstract}
Keywords

- NEC

- premature infant

- questionnaire

Aim The aim of this study is to define patterns in the management of necrotizing enterocolitis (NEC).

Methods A total of 80 delegates (81\% senior surgeons) from 29 (20 European) countries completed a survey at the European Pediatric Surgeons' Association 2013 annual meeting.

Results Overall, 59\% surgeons work in centers where $>10$ cases of NEC are treated per year. Diagnosis: $76 \%$ surgeons request both anteroposterior and lateral abdominal Xrays, which are performed at regular intervals by $66 \%$; $50 \%$ surgeons also request Doppler ultrasonography; most frequently used biochemical markers are platelets (99\% of surgeons), C-reactive protein (90\%), and white cell count (83\%). Laparoscopy is performed for diagnosis and/or treatment of NEC by only $8 \%$ surgeons. Overall, $43 \%$ surgeons reported being able to diagnose focal intestinal perforation preoperatively. Medical NEC: medical NEC is managed by surgical and neonatal teams together in most centers (84\%). Most surgeons (67\%) use a combination of two $(51 \%)$ or three $(48 \%)$ antibiotics for more than 7 days, and keep patients nil by mouth for 7 (41\%) or 10 (49\%) days. Surgical NEC: In extremely low-birth-weight infants $(<1,000 \mathrm{~g})$ with intestinal
\end{abstract}

received

May 15, 2014

accepted

June 23, 2014

published online

October 26, 2014 (c) 2015 Georg Thieme Verlag KC

Stuttgart · New York
DOI http://dx.doi.org/ 10.1055/s-0034-1387942. ISSN 0939-7248. 
perforation, $27 \%$ surgeons opt for primary peritoneal drainage (PPD) as definitive treatment. Overall, 67\% think that peritoneal drainage is important for stabilization and transport. At laparotomy, treatments vary according to NEC severity. About 75\% surgeons always close the abdomen, and $29 \%$ leave a patch to prevent compartment syndrome. Postoperative management: Infants are kept nil by mouth for 5 to 7 days by $46 \%$ surgeons, more than 7 days by $42 \%$, and less than 5 days by $12 \%$ surgeons. Most surgeons $(77 \%)$ restart infants on breast milk, $11.5 \%$ on aminoacid-based formulas, and $11.5 \%$ on hydrolyzed formulas. Most surgeons (92\%) follow-up NEC patients after discharge, up to 5 years of life (56\%) and $65 \%$ surgeons organize a neurodevelopmental follow-up.

Conclusions Many aspects of NEC management are lacking consensus and surgeons differ especially over surgical treatment of complex cases and postoperative management. Prospective multi-center studies are needed to guide an evidence-based management of NEC.

\section{Introduction}

Necrotizing enterocolitis (NEC) is a devastating disease of newborn infants, first described in the literature by Schmid and Quaiser in 1953 as enterocolitis ulcerosa necroticans. ${ }^{1,2}$ Despite extensive research and advancement in medical and surgical treatment over the last six decades, NEC still represents a challenging condition with a mortality rate as high as $40 \%$, especially in extremely low-birth-weight (ELBW) infants. ${ }^{3}$ Controversy persists as to the most appropriate management of NEC, although several randomized controlled trials have been conducted to question or define the evidence of various aspects of prevention and treatment of this condition.

The aim of this study was to present current views of pediatric surgeons on their management of NEC, and to ascertain the degree of variability among pediatric surgical centers.

\section{Methods}

A questionnaire was administered to delegates attending the 14th Congress of the European Pediatric Surgeons' Association (EUPSA; Leipzig, Germany, June 5-8, 2013) and collected on the last day of the conference. Respondents were asked to fill in their position (Head of Department/Permanent Staff or Consultant/Trainee), hospital, and country of practice.

The questionnaire focused on the preoperative imaging and laboratory work-up, management of medically treated NEC, surgical aspects, postoperative management, and follow-up (-Fig. 1).

A total of 80 delegates, including 14 heads of department, 47 consultants, and 14 trainees, completed the questionnaire. Five delegates did not disclose their degree.

On 76 questionnaires, respondents reported their country of origin. Overall, 64 were from 20 European countries (84\%) and 12 from 9 non-European countries (16\%).

\section{Results}

\section{Center}

Overall, 23 (29\%) respondents work in centers that treat 5 to 10 cases of NEC a year, 26 (33\%) reported working in a center that treats 10 to $25 \mathrm{NEC}$ cases a year, and 21 (26\%) in a center that treats more than 25 NEC cases a year. Only $10(12 \%)$ respondents work in a center that treats less than 5 NEC cases a year.

\section{Diagnosis}

In the work-up of patients with suspected NEC, 61 (76\%) surgeons request both anteroposterior and lateral abdominal $\mathrm{X}$-rays, and $53(66 \%)$ of them request abdominal X-rays at regular intervals to monitor patient status-37\% every 6 to 12 hours, $22 \%$ every 12 to 24 hours, $22 \%$ on alternate days, and $19 \%$ every 3 days. Beyond plain X-rays, 40 (50\%) surgeons request intestinal Doppler ultrasonography, whereas only 1 surgeon reports the use of abdominal magnetic resonance imaging (MRI) scans. Only six (8\%) surgeons would consider laparoscopy for diagnosis and/or treatment of NEC.

Of the responding surgeons, 32 (43\%) reported that they are able to diagnose focal intestinal perforation preoperatively.

The most commonly used biochemical markers are reported in - Fig. 2. Surgeons rely the most on platelet count (99\%), C-reactive protein concentration (90\%), and/or white blood cell count (83\%), and in smaller proportions on lactate levels (43\%) (-Fig. 2).

\section{Medical Necrotizing Enterocolitis}

Most surgeons $(67,84 \%)$ report that medical NEC is managed by surgical and neonatal teams together, whereas fewer of these patients are managed by neonatologists $(11,14 \%)$ or surgeons alone (2, $2 \%)$.

Two thirds of surgeons (52,67\%) keep patients with NEC on antibiotics for more than 7 days, whereas the remaining third $(23,34 \%)$ for up to 7 days. A combination of two, three, or 


\section{EUPSA Network: Necrotizing Enterocolitis Survey}

Head of Department / Permanent Staff or Convultant / Trainee igiease circle as apsropriate)
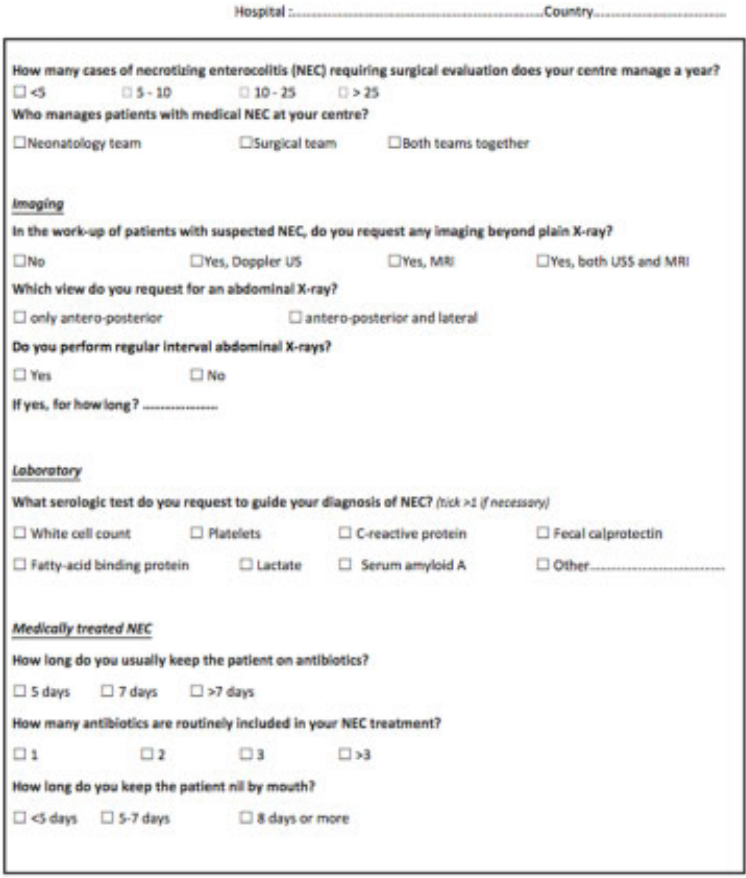

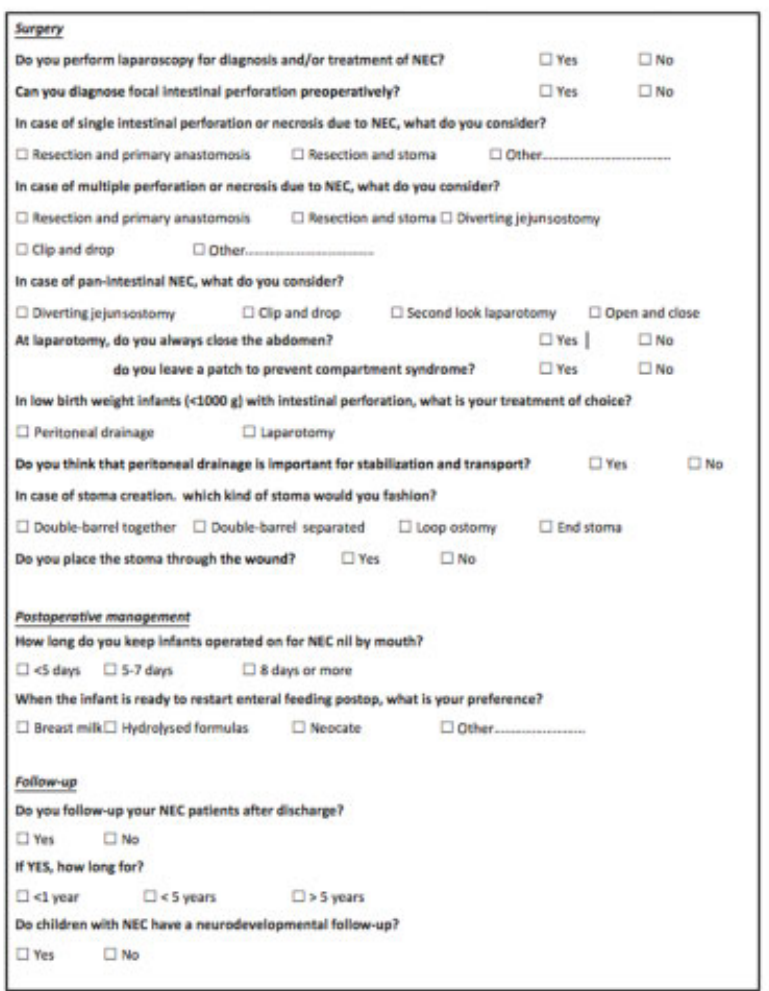

Fig. 1 The questionnaire administered to delegates attending the 14th EUPSA Congress, Leipzig, Germany, June 5 to 8, 2013.

more than three antibiotics are administered to medically managed NEC patients, by 40 (51\%), 37 (48\%), and 1 (1\%) responders, respectively. Patients are kept nil by mouth for less than 5 days by 8 (10\%) responders, between 5 and 7 days by 31 (41\%), and for 8 days or more by 38 (49\%) responders.

\section{Surgical Necrotizing Enterocolitis}

In ELBW infants $(<1,000 \mathrm{~g})$ with intestinal perforation, 57 (73\%) surgeons would perform a laparotomy, whereas 21 (27\%) would opt for PPD as definitive treatment ( - Fig. 3A). Forty-eight (67\%) surgeons consider PPD insertion important

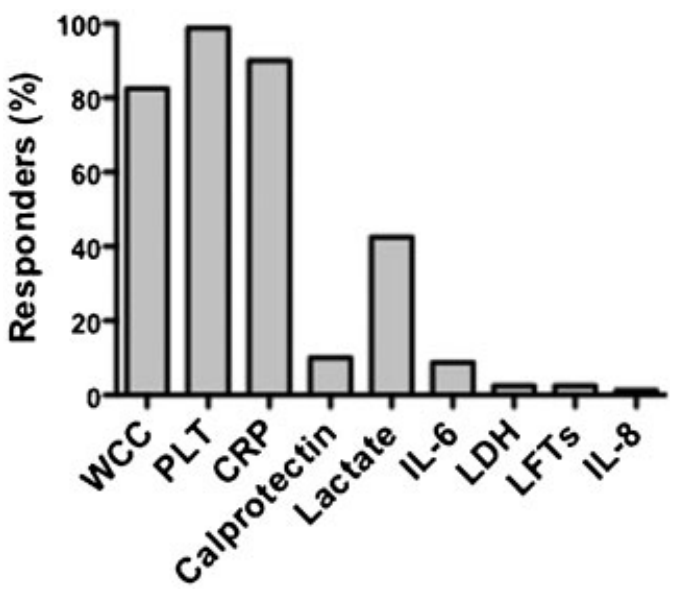

Fig. 2 The most commonly used biochemical markers for diagnosis and monitoring of NEC. CRP, C-reactive protein;IL-6, interleukin 6; IL-8, interleukin 8; LDH, lactate dehydrogenase; LFTs, liver function tests; PLT, platelets; WCC, white cell count. for stabilization and transport of very sick infants with NEC. At laparotomy, treatment varies according to NEC severity (-Fig. 3B). Where there is a single perforation or area of necrosis, 53 (67\%) surgeons would opt for bowel resection and anastomosis, 25 (32\%) would create a stoma, and only 1 (1\%) would oversew the perforation site. In case of multiple perforations or areas of necrosis, 51 (68\%) surgeons would create a stoma, 11 (15\%) would opt for bowel resection and anastomosis, 7 (9\%) would create a diverting jejunostomy, 5 (7\%) would opt for clip and drop technique, and 1 (1\%) would opt for fashion multiple stomas. In case of pan intestinal NEC, 32 (43\%) would opt for a second-look laparotomy, 26 (35\%) for a diverting jejunostomy, 12 (16\%) for clip and drop technique, 2 (3\%) would close the abdomen without carrying out any procedure, and 2 (3\%) would create a stoma.

In case of stoma creation, 34 (43\%) surgeons prefer the double barrel, 27 (34\%) the separated stoma, 16 (20\%) the loop ostomy, and 2 (3\%) the end ostomy. Moreover, 40 (51\%) surgeons would place the stoma within the wound.

At laparotomy, 57 (75\%) surgeons always close the abdomen, whereas 19 (25\%) would not, depending on the circumstances. To prevent compartment syndrome, 20 (29\%) surgeons leave a patch, but the majority $(49,71 \%)$ would not.

\section{Postoperative Management}

Postoperatively, infants are kept nil by mouth for 5 to 7 days by 36 (46\%) surgeons, more than 7 days by 33 (42\%), and less than 5 days by 9 (12\%) surgeons. Most surgeons (54, 77\%) restart infants on breast milk, $8(11.5 \%)$ on Neocate, and 8 (11.5\%) on hydrolyzed formulas. 

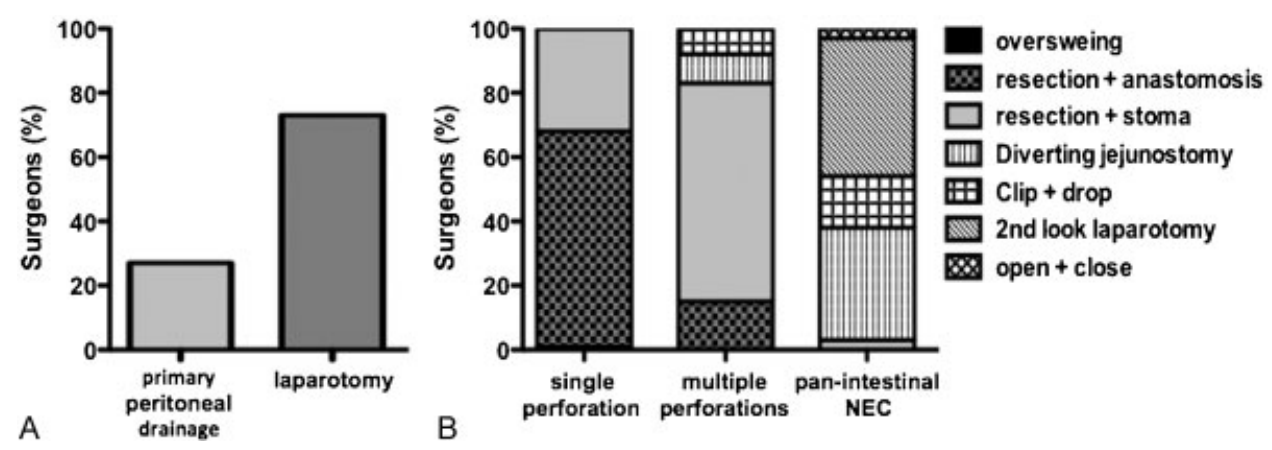

Fig. 3 (A) Treatment options in extremely low-birth-weight infants with intestinal perforation. (B) Surgical options according to NEC severity. NEC, necrotizing enterocolitis.

\section{Follow-Up}

After hospital discharge, only a few (6, 8\%) surgeons responded that NEC patients are followed up by the neonatal team alone, whereas the majority $(74,92 \%)$ of surgeons responded that infants are followed up in the clinic by the surgeons. Of those that follow-up patients, 22 (31\%) surgeons review NEC patients for a maximum of 1 year, 40 (56\%) up to 5 years of age, and 10 (13\%) beyond 5 years of age. Finally, $51(65 \%)$ surgeons request a specific neurodevelopmental follow-up for their NEC patients.

\section{Discussion}

This survey of practice highlighted the lack of consensus on different aspects of NEC management.

The incidence of NEC is subject to a degree of variability according to geographical and ethnical distribution, with lower frequencies in Japan, Switzerland, and Austria and higher frequencies in Northern America, United Kingdom, and Ireland. ${ }^{4-10}$ It is still unknown whether this incidence variability is due to actual genetic and/or environmental factors in the population or whether it is influenced by neonatal care strategies regardless the ethnical background. Several authors have successfully reported strategies to prevent NEC in premature infants at risk, mainly consisting of early trophic feeding with human breast milk, administration of antibiotics and/or antifungal agents, and enteral administration of probiotics. ${ }^{8,11} \mathrm{NEC}$ incidence variability is mirrored by the results of this survey with different number of NEC cases reported by delegates from different countries.

Plain anteroposterior and left lateral decubitus radiography is the cornerstone of NEC diagnosis and staging, ${ }^{12,13}$ and is performed at variable intervals according to personal surgeon choice, as shown by our survey. Doppler ultrasonography, especially aimed at measuring blood flow velocity in the celiac trunk and superior mesenteric artery, has been used to identify patients at risk of developing NEC, ${ }^{14}$ as well as to assess the bowel viability in those infants with established NEC. ${ }^{15-18}$ In particular, sonographic findings of free gas, focal fluid collection, increased bowel wall echogenicity, absent bowel perfusion, portal venous gas, bowel wall thinning or thickening, and intramural gas are associated with adverse outcome. ${ }^{19}$ According to our survey, $50 \%$ surgeons rely on intestinal Doppler ultrasonography beyond plain radiography, thus confirming that this imaging modality adds useful information in NEC clinical practice. Conversely, the use of MRI scan in human NEC, described only once in the literature, ${ }^{20}$ still remains anecdotal.

Infants with NEC typically present with neutropenia, thrombocytopenia, metabolic acidosis, and high C-reactive protein levels. ${ }^{13}$ In our study, the vast majority of surgeons indeed rely upon these parameters for the diagnosis and monitoring of patient clinical status. Over the last two decades, other markers have been identified in the serum, urine, and feces in both animal and human studies. ${ }^{21-30}$ According to this survey, $10 \%$ of surgeons rely on fecal calprotectin and approximately 10\% on interleukins 6 or 8 , whereas fatty acid binding protein and serum amyloid A do not seem to be part of routine clinical practice. Possibly, this is because of the fact that for some of these factors, there is no clinical evidence of their utility in the literature.

Several authors have reported the use of laparoscopy to diagnose NEC. ${ }^{31-34}$ Pierro et al reported that laparoscopy can provide important information regarding bowel viability, it is feasible and tolerated even in infants weighing less than $1 \mathrm{~kg}$, and can be safely performed on the intensive care unit. ${ }^{31}$ Moreover, Numanoglu and Millar reported that when bowel ischemia is suspected, fluorescein laparoscopy could be useful to identify the necrotic segments. ${ }^{33}$ On the contrary, some authors have reported cases of infants who developed paradoxical carbon dioxide embolism secondary to pneumoperitoneum. ${ }^{35-37}$ According to our survey, only a minority of surgeons (8\%) would consider laparoscopy in infants with NEC.

A long debated question in NEC literature is whether focal intestinal perforation is to be considered as a separate pathological entity or a variant along the spectrum of the NEC. Some authors have reported the difficulty of relying on radiological features to distinguish the extension of the disease. $^{38,39}$ Interestingly, $43 \%$ surgeons responding to our survey claim to be able to distinguish focal intestinal perforation preoperatively and this could have an impact on their management plans. This might be explained by the fact that some surgeons would predict focal intestinal perforation preoperatively by interpreting the abdominal X-ray in a patient with a clinical history of antenatal and/or postnatal 
corticosteroids, early use of indomethacin, sudden onset of pneumoperitoneum. ${ }^{40-45}$

Most infants with suspected (Bell's stage 1) or confirmed (Bell's stage 2) NEC are managed nonoperatively, and according to our survey surgeons are crucially involved in the management of these infants. Nonoperative treatment includes ventilatory support, fluid resuscitation, inotropic support as required, correction of acid-base imbalance, coagulopathy, and/or thrombocytopenia, bowel rest and antibiotics. ${ }^{46}$ The latter are administered for more than 7 days by two thirds of the surgeons responding to our survey. Currently, there is no consensus in the literature on which antibiotic regimen should be prescribed for medically managed NEC infants, and this is reflected by the answers to our questionnaire, too. A recent Cochrane review highlighted the lack of evidence to recommend a particular antibiotic regimen and reported the potential adverse outcome following clindamycin use, which could result in intestinal stricture development. ${ }^{47}$ Antibiotics are prescribed depending on institutional protocol and changed according to individual culture and sensitivity results. Similarly, there is no evidence on the duration of bowel rest and nil by mouth regimen for medically treated NEC infants and variation of practice have been recorded by our survey.

A proportion of medically managed NEC infants require acute surgical intervention, due to clinical deterioration or intestinal perforation. Performing a laparotomy in high-risk neonates, especially if ELBW, might result in serious morbidity or even mortality. To avoid this risk, in 1974, Ein et al first described that infants treated with peritoneal drainage, initially conceived as a temporizing measure, actually survived and needed no laparotomy. ${ }^{48}$ This experience with PPD was also later reported by other authors. ${ }^{49-51}$ However, two prospective randomized controlled trials comparing the use of PPD in infants with perforated NEC with laparotomy failed to demonstrate an advantage of one treatment modality over the other. ${ }^{52,53}$ Moreover, Pierro et al demonstrated that PPD was not an effective definitive procedure for infants with perforated NEC because $74 \%$ infants required a rescue laparotomy. ${ }^{54}$ In spite of this evidence, our survey showed that $27 \%$ of respondents opt for PPD as definitive treatment (-Fig. 3A). It is still debatable whether there is a role for PPD in the stabilization of a critically unwell child with perforated NEC and/or respiratory compromise before transfer to another center for a laparotomy. ${ }^{54}$ According to our survey, two thirds of the responding surgeons use PPD in their practice in such cases.

The universal principles of surgery in the NEC are to remove necrotic intestine and control intra-abdominal sepsis while preserving as much intestinal length as possible. ${ }^{46}$ Within these principles, there are different surgical options that surgeons favor on the basis of personal experience, rather than evidence-based literature ( - Fig. 3B). According to our survey, in case of single perforation or area of necrosis the majority of surgeons would opt for bowel resection and anastomosis, whereas in case of multiple perforation or areas of necrosis, the majority would create a stoma. However, this survey mainly reflects the view of pediatric surgeons from
Europe, as the use of primary anastomosis can be less frequent in Northern America. ${ }^{55}$ The scenario of pan intestinal NEC remains the most controversial. Interestingly, the clip and drop technique, first described by Vaughan et al in 1996 in three patients with NEC and two patients with midgut volvulus, ${ }^{56}$ and later supported by other studies, ${ }^{57,58}$ is favored only by a minority of surgeons responding to our survey.

Similarly, there is no consensus on the type of stoma to fashion and where to locate it with regards to the surgical wound. This is in line with the outcomes of a recent systematic review of the literature that showed no difference in the type or location of colostomy in children with colorectal disease. $^{59}$

It is known that sometimes NEC can be complicated by the abdominal compartment syndrome, in which case options include the use of patches or silos. ${ }^{60,61}$ However, the present survey shows that the general tendency is to attempt abdominal closure and to avoid the use of patches.

In the postoperative period, there is variability among the respondents regarding the duration of bowel rest. Conversely, it is not surprising to observe an agreement on the postoperative use of breast milk, whose role in NEC prevention is well documented. ${ }^{62-64}$

Following hospital discharge, NEC survivors are at risk of various morbidities, including development of intestinal strictures, intestinal failure, parenteral nutrition related complications, and neurodevelopmental disabilities. ${ }^{65,66}$ Therefore, follow-up of these patients is essential. ${ }^{67,68}$ This survey showed that the vast majority of surgeons do follow-up their patients, for a period that is subjective to personal practice. Moreover, two thirds of surgeons are aware of the potential neurological sequelae and request a specific neurodevelopmental follow-up for their NEC patients.

In conclusion, some aspects of NEC management are lacking consensus and surgeons differ especially over surgical treatment of complex cases, such as pan intestinal NEC. Randomized controlled trials are necessary to guide an evidence-based management of patients with NEC; however, proven policies should have greater general acceptance and be introduced into the clinic.

Conflict of Interest

None.

\section{References}

1 Schmid KO. Über eine besonders schwer verlaufende form von enteritis beim säugling, "enterocolitis ulcerosa necroticans". I. Pathologisch-anatomische Studien. Österr Z Kinderh und Kinderf 1953;8:114-136

2 Quaiser K. Über eine besonders schwer verlaufende form von enteritis beim säugling, "enterocolitis ulcerosa necroticans" II. Klinische Studien. Österr Z Kinderh und Kinderf 1953;8: 136-152

3 Fitzgibbons SC, Ching Y, Yu D, et al. Mortality of necrotizing enterocolitis expressed by birth weight categories. J Pediatr Surg 2009;44(6):1072-1075, discussion 1075-1076 
4 Kosloske AM. Epidemiology of necrotizing enterocolitis. Acta Paediatr Suppl 1994;396:2-7

5 Sankaran K, Puckett B, Lee DSC, et al; Canadian Neonatal Network. Variations in incidence of necrotizing enterocolitis in Canadian neonatal intensive care units. J Pediatr Gastroenterol Nutr 2004; 39(4):366-372

6 Holman RC, Stoll BJ, Curns AT, Yorita KL, Steiner CA, Schonberger LB. Necrotising enterocolitis hospitalisations among neonates in the United States. Paediatr Perinat Epidemiol 2006;20(6):498-506

7 Kawase Y, Ishii T, Arai H, Uga N. Gastrointestinal perforation in very low-birthweight infants. Pediatr Int 2006;48(6):599-603

8 Schmolzer G, Urlesberger B, Haim M, et al. Multi-modal approach to prophylaxis of necrotizing enterocolitis: clinical report and review of literature. Pediatr Surg Int 2006;22(7):573-580

9 Guner YS, Friedlich P, Wee CP, Dorey F, Camerini V, Upperman JS. State-based analysis of necrotizing enterocolitis outcomes. J Surg Res 2009;157(1):21-29

10 Rees CM, Eaton S, Pierro A. National prospective surveillance study of necrotizing enterocolitis in neonatal intensive care units. J Pediatr Surg 2010;45(7):1391-1397

11 AlFaleh K, Anabrees J. Probiotics for prevention of necrotizing enterocolitis in preterm infants. Cochrane Database Syst Rev 2014; 4:CD005496

12 Bell MJ, Ternberg JL, Feigin RD, et al. Neonatal necrotizing enterocolitis. Therapeutic decisions based upon clinical staging. Ann Surg 1978;187(1):1-7

13 Kim SS, Albanese CT. Necrotizing enterocolitis. In: O'Neill JA, Coran AG, Fonkalsrud E, Grosfeld JL, eds. Pediatric Surgery. 6th ed. St. Louis, MO: Mosby; 2003:1427-1452

14 Murdoch EM, Sinha AK, Shanmugalingam ST, Smith GC, Kempley ST. Doppler flow velocimetry in the superior mesenteric artery on the first day of life in preterm infants and the risk of neonatal necrotizing enterocolitis. Pediatrics 2006;118(5):1999-2003

15 Kempley ST, Gamsu HR. Superior mesenteric artery blood flow velocity in necrotising enterocolitis. Arch Dis Child 1992;67(7 Spec No):793-796

16 Deeg KH, Rupprecht T, Schmid E. Doppler sonographic detection of increased flow velocities in the celiac trunk and superior mesenteric artery in infants with necrotizing enterocolitis. Pediatr Radiol 1993;23(8):578-582

17 Fotter R, Sorantin E. Diagnostic imaging in necrotizing enterocolitis. Acta Paediatr Suppl 1994;396:41-44

18 Faingold R, Daneman A, Tomlinson G, et al. Necrotizing enterocolitis: assessment of bowel viability with color doppler US. Radiology 2005;235(2):587-594

19 Silva CT, Daneman A, Navarro OM, et al. Correlation of sonographic findings and outcome in necrotizing enterocolitis. Pediatr Radiol 2007;37(3):274-282

20 Maalouf EF, Fagbemi A, Duggan PJ, et al. Magnetic resonance imaging of intestinal necrosis in preterm infants. Pediatrics 2000;105(3 Pt 1):510-514

21 Gollin G, Marks WH. Elevation of circulating intestinal fatty acid binding protein in a luminal contents-initiated model of NEC J Pediatr Surg 1993;28(3):367-370, discussion 370-371

22 Morecroft JA, Spitz L, Hamilton PA, Holmes SJ. Plasma interleukin6 and tumour necrosis factor levels as predictors of disease severity and outcome in necrotizing enterocolitis. J Pediatr Surg 1994;29(6):798-800

23 Carroll D, Corfield A, Spicer R, Cairns P. Faecal calprotectin concentrations and diagnosis of necrotising enterocolitis. Lancet 2003;361(9354):310-311

24 Cetinkaya M, Ozkan H, Köksal N, Akaci O, Ozgür T. The efficacy of serial serum amyloid A measurements for diagnosis and follow-up of necrotizing enterocolitis in premature infants. Pediatr Surg Int 2010;26(8):835-841

25 Thuijls G, Derikx JP, van Wijck K, et al. Non-invasive markers for early diagnosis and determination of the severity of necrotizing enterocolitis. Ann Surg 2010;251(6):1174-1180
26 Benkoe T, Reck C, Gleiss A, et al. Interleukin 8 correlates with intestinal involvement in surgically treated infants with necrotizing enterocolitis. J Pediatr Surg 2012;47(8):1548-1554

27 Selimoğlu MA, Temel I, Yıldııım Ç, Özyaln F, Aktaş M, Karabiber H. The role of fecal calprotectin and lactoferrin in the diagnosis of necrotizing enterocolitis. Pediatr Crit Care Med 2012;13(4): 452-454

28 Ng EW, Poon TC, Lam HS, et al. Gut-associated biomarkers L-FABP, I-FABP, and TFF3 and LIT score for diagnosis of surgical necrotizing enterocolitis in preterm infants. Ann Surg 2013;258(6): 1111-1118

29 Benkoe T, Reck C, Pones M, et al. Interleukin-8 predicts 60-day mortality in premature infants with necrotizing enterocolitis. J Pediatr Surg 2014;49(3):385-389

30 Reisinger KW, Kramer BW, Van der Zee DC, et al. Non-invasive serum amyloid A (SAA) measurement and plasma platelets for accurate prediction of surgical intervention in severe necrotizing enterocolitis (NEC). PLoS ONE 2014;9(3):e90834

31 Pierro A, Hall N, Ade-Ajayi A, Curry J, Kiely Em EM. Laparoscopy assists surgical decision making in infants with necrotizing enterocolitis. J Pediatr Surg 2004;39(6):902-906, discussion 902906

32 Leva E, Di Cesare A, Canazza L, et al. The role of laparoscopy in newborns affected by NEC. J Laparoendosc Adv Surg Tech A 2010; 20(2):187-189

33 Numanoglu A, Millar AJ. Necrotizing enterocolitis: early conventional and fluorescein laparoscopic assessment. J Pediatr Surg 2011;46(2):348-351

34 Smith J, Thyoka M. What role does laparoscopy play in the diagnosis and immediate treatment of infants with necrotizing enterocolitis? J Laparoendosc Adv Surg Tech A 2013;23(4): 397-401

35 Kudsi OY, Jones SA, Brenn BR. Carbon dioxide embolism in a 3-week-old neonate during laparoscopic pyloromyotomy: a case report. J Pediatr Surg 2009;44(4):842-845

36 Taylor SP, Hoffman GM. Gas embolus and cardiac arrest during laparoscopic pyloromyotomy in an infant. Can J Anaesth 2010; 57(8):774-778

37 Fischler M. Occurrence of a carbon dioxide embolism during laparoscopic pyloromyotomy in a small child: several unresolved questions. Can J Anaesth 2011;58(2):226, author reply 226-227

38 Tam AL, Camberos A, Applebaum H. Surgical decision making in necrotizing enterocolitis and focal intestinal perforation: predictive value of radiologic findings. J Pediatr Surg 2002;37(12): $1688-1691$

39 Hwang H, Murphy JJ, Gow KW, Magee JF, Bekhit E, Jamieson D. Are localized intestinal perforations distinct from necrotizing enterocolitis? J Pediatr Surg 2003;38(5):763-767

40 Attridge JT, Clark R, Gordon PV. New insights into spontaneous intestinal perforation using a national data set (3): antenatal steroids have no adverse association with spontaneous intestinal perforation. J Perinatol 2006;26(11):667-670

41 Attridge JT, Clark R, Walker MW, Gordon PV. New insights into spontaneous intestinal perforation using a national data set: (2) two populations of patients with perforations. J Perinatol 2006; 26(3):185-188

42 Attridge JT, Clark R, Walker MW, Gordon PV. New insights into spontaneous intestinal perforation using a national data set: (1) SIP is associated with early indomethacin exposure. J Perinatol 2006;26(2):93-99

43 Paquette L, Friedlich P, Ramanathan R, Seri I. Concurrent use of indomethacin and dexamethasone increases the risk of spontaneous intestinal perforation in very low birth weight neonates. J Perinatol 2006;26(8):486-492

44 Gordon PV, Swanson JR, Attridge JT, Clark R. Emerging trends in acquired neonatal intestinal disease: is it time to abandon Bell's criteria? J Perinatol 2007;27(11):661-671 
45 Bohnhorst B, Kuebler JF, Rau G, Gluer S, Ure B, Doerdelmann M. Portal venous gas detected by ultrasound differentiates surgical NEC from other acquired neonatal intestinal diseases. Eur J Pediatr Surg 2011;21(1):12-17

46 Hall NJ, Eaton S, Pierro A. Royal Australasia of Surgeons Guest Lecture. Necrotizing enterocolitis: prevention, treatment, and outcome. J Pediatr Surg 2013;48(12):2359-2367

47 Shah D, Sinn JK. Antibiotic regimens for the empirical treatment of newborn infants with necrotising enterocolitis. Cochrane Database Syst Rev 2012;8:CD007448

48 Ein SH, Marshall DG, Girvan D. Peritoneal drainage under local anesthesia for perforations from necrotizing enterocolitis.J Pediatr Surg 1977;12(6):963-967

49 Lessin MS, Luks FI, Wesselhoeft CW Jr, Gilchrist BF, Iannitti D, DeLuca FG. Peritoneal drainage as definitive treatment for intestinal perforation in infants with extremely low birth weight (<750 g). J Pediatr Surg 1998;33(2):370-372

50 Rovin JD, Rodgers BM, Burns RC, McGahren ED. The role of peritoneal drainage for intestinal perforation in infants with and without necrotizing enterocolitis. J Pediatr Surg 1999;34(1): 143-147

51 Goyal A, Manalang LR, Donnell SC, Lloyd DA. Primary peritoneal drainage in necrotising enterocolitis: an 18-year experience. Pediatr Surg Int 2006;22(5):449-452

52 Moss RL, Dimmitt RA, Barnhart DC, et al. Laparotomy versus peritoneal drainage for necrotizing enterocolitis and perforation. N Engl J Med 2006;354(21):2225-2234

53 Rees CM, Eaton S, Kiely EM, Wade AM, McHugh K, Pierro A. Peritoneal drainage or laparotomy for neonatal bowel perforation? A randomized controlled trial. Ann Surg 2008;248(1):44-51

54 Pierro A, Eaton S, Rees CM, et al. Is there a benefit of peritoneal drainage for necrotizing enterocolitis in newborn infants? J Pediatr Surg 2010;45(11):2117-2118

55 Downard CD, Renaud E, St Peter SD, et al; 2012 American Pediatric Surgical Association Outcomes Clinical Trials Committee. Treatment of necrotizing enterocolitis: an American Pediatric Surgical Association Outcomes and Clinical Trials Committee systematic review. J Pediatr Surg 2012;47(11):2111-2122

56 Vaughan WG, Grosfeld JL, West K, Scherer LR III, Villamizar E, Rescorla FJ. Avoidance of stomas and delayed anastomosis for bowel necrosis: the 'clip and drop-back' technique. J Pediatr Surg 1996;31(4):542-545

57 Ron O, Davenport M, Patel S, et al. Outcomes of the "clip and drop" technique for multifocal necrotizing enterocolitis. J Pediatr Surg 2009;44(4):749-754

58 Pang KK, Chao NS, Wong BP, Leung MW, Liu KK. The clip and drop back technique in the management of multifocal necrotizing enterocolitis: a single centre experience. Eur J Pediatr Surg 2012;22(1):85-90

59 van den Hondel D, Sloots C, Meeussen C, Wijnen R. To split or not to split: colostomy complications for anorectal malformations or hirschsprung disease: a single center experience and a systematic review of the literature. Eur J Pediatr Surg 2014;24(1):61-69

60 Neville HL, Lally KP, Cox CS Jr. Emergent abdominal decompression with patch abdominoplasty in the pediatric patient. J Pediatr Surg 2000;35(5):705-708

61 Moore AB, Nakayama DK. Preformed silastic silos in the management of necrotizing enterocolitis. Am Surg 2009;75(2):172-174

62 Lucas A, Cole TJ. Breast milk and neonatal necrotising enterocolitis. Lancet 1990;336(8730):1519-1523

63 Quigley MA, Henderson G, Anthony MY, McGuire W. Formula milk versus donor breast milk for feeding preterm or low birth weight infants. Cochrane Database Syst Rev 2007;4(4):CD002971

64 Meinzen-Derr J, Poindexter B, Wrage L, Morrow AL, Stoll B, Donovan EF. Role of human milk in extremely low birth weight infants' risk of necrotizing enterocolitis or death. J Perinatol 2009; 29(1):57-62

65 Hintz SR, Kendrick DE, Stoll BJ, et al; NICHD Neonatal Research Network. Neurodevelopmental and growth outcomes of extremely low birth weight infants after necrotizing enterocolitis. Pediatrics 2005;115(3):696-703

66 Rees CM, Pierro A, Eaton S. Neurodevelopmental outcomes of neonates with medically and surgically treated necrotizing enterocolitis. Arch Dis Child Fetal Neonatal Ed 2007;92(3): F193-F198

67 Simon NP. Follow-up for infants with necrotizing enterocolitis. Clin Perinatol 1994;21(2):411-424

68 Stanford A, Upperman JS, Boyle P, Schall L, Ojimba JI, Ford HR. Longterm follow-up of patients with necrotizing enterocolitis. J Pediatr Surg 2002;37(7):1048-1050, discussion 1048-1050 